Galería 



\title{
José Tola: testimonio
}

\author{
Alfonso Cisneros Cox
}

\section{Introducción}

A lo largo de los años y luego de haber atravesado diversos períodos que comprenden las litografías y xilografías, el trabajo en caladas y sobre extensas superficies de madera, el papel, la tradicional tela, el indomable plástico (que formó parte de sus ensamblajes) y el vidrio -y habiendo abandonado hace mucho tiempo el discurso tradicional y el formato común y conocido de la pintura (no solo en aspecto sino también en forma y contenido)-, José Tola se nos muestra hoy como un ser de un lenguaje excepcional, de naturaleza contemplativa y de leyenda, y expresa un completo y paralelo universo de compleja traducción e interpretación: el diario y diurno subjetivo sobre objetivo; aquella eterna lucha de dominación entre las razones y las racionalidades; o, en nuestros días, un universo de sucesos impalpables polarizados por el cotidiano, que solo un verdadero observador es capaz de relatar. En su propio lenguaje, claro está.

Así, a partir de una entrevista de veinte preguntas, José Tola nos relató algo más que ello: una sincera y colmada interpretación de los 
años de su vida, de sus procesos y cambios, de las relaciones y decepciones de tener todo el tiempo que se tiene en esta tierra; nos ofrece un mensaje de claridad a través de su obra, sin simbolizar ni representar realidades patéticas, mas sí emblematizando los "horrores" de nuestra propia contemporaneidad y sintiéndolos sin referirse a las causas que los propiciaron. Es así como - a nuestros ojos- José Tola llega a un nivel de polisemia absoluto; a aquello que el estudioso Juan Acha denominó una vez "espejos mágicos de horrores contemporáneos".

De ello trata el testimonio que presentamos a continuación. Una obra completa de sinceridad, color e historia en el lenguaje personal del artista.

\section{De lo bello, lo feo y lo desagradable}

En su tiempo, la frase del filósofo Kant pudo resultar una argumentación lapidaria al confrontar los conceptos de lo feo y lo bello, desdeñando lo desagradable a un nivel despectivo. El arte moderno, que empieza con una caravana de incongruencias haciendo uso de lo desagradable, lo feo, lo bello -y todo sinónimo de cada uno de ellos- como parte de la estética del artista y de la sociedad de hoy, no es más que parte de una evolución de nuestra historia.

No hay cánones que el artista respete, como en épocas pasadas... Hoy el artista aspira a una libertad absoluta, sin consideración de tales conceptos, y las antinomias de Kant son ya una mera concepción de lo inútil. Nadie en el mundo de hoy pretende ya crear belleza en ese sentido estricto de la palabra.

El concepto tradicional de belleza es caduco; lo mismo ocurre con lo feo y lo desagradable... Son, todos, conceptos de la farándula de lo que ha empezado a ser el arte. De este modo, hasta la imbecilidad tiene una mueca de lo más aceptable...

Reivindiquemos pues a Kant, para ser imperdonables. Veamos como ejemplo al "radicalista" Joseph Beuys, quien llegó a vociferar que "todo hombre era un artista", y recordemos también aquello que llamó recital, que podemos describir como a Beuys, de pie, inmóvil y solo en un escenario, llorando. 
Eso era todo... Beuys en un llanto sin motivación, sin poder uno entender el porqué de ese lloriqueo, de esa sola secuencia de lágrimas incongruentes en un rostro como el de Buster Keaton en la época del cine mudo...

Beuys denomina su creación "Celtic". Y qué es Celtic si no quizá una demostración de absoluta libertad, equiparable, entre otras, a un Arcimboldo - de fines del 1500 - con su delirante art mortis de rostros compuestos de elementos vegetales y animales.

Coetáneo -y sin ir más lejos- encontramos a Ives Klein y su IKB (Internacional Klein Blue) en su recurrente fórmula de uso de monótonos azules sintéticos, llevados también hasta sus performances, en las que se podía apreciar a mujeres pintadas todas de ese mismo azul aglutinado con Rhodopas M 60 A.

Y hay tantas más modalidades expresivas en este pasado siglo y hasta nuestros días... Warhol, por ejemplo, con la "súper producción de plano fijo" rodada durante ocho horas continuas en el verano de 1964, titulada The Empire State Building.

Y qué decir de Tzara, Pollock, Stella, Niké de Saint-Phalle..., o John Cage con su gran Paisaje imaginario número cuatro, donde la música era ejecutada con doce o trece receptores de radio a los cuales "los músicos" subían y bajaban el volumen continuamente cambiando única y permanentemente la frecuencia del sonido.

Ahora podemos entender por qué Francis Bacon decía que en nuestro tiempo el arte solo podía ser un juego... Un juego como el de Mathieu, quien pintó un cuadro de quince metros de largo en una hora en Tokio, sosteniendo como teoría que la velocidad abolía todo canon artístico.

Igualmente, Mondrian - en ese mismo siglo- era un pintor con una versatilidad extraordinaria. Transitó desde aquel paisajismo tonal de la tradicional Escuela de La Haya hasta el Cubismo, pasando por el Impresionismo, el Fauvismo y una versión tardía del Divisionismo. Fue apreciado por mantener una actitud tan estoica con esa simplicidad de los colores primarios y líneas verticales y horizontales, hasta llegar a Broadway Boogie Woogie, y eso fue todo. 


\section{La pintura}

Ahora, es posible que aquella antigua definición de lo que es la pintura no sea válida, como sucede con todas las demás ramas del arte, donde no existe una fórmula absoluta de $x+2 \ldots$

No puedo dejar de pensar en manifestaciones paralelas de esos tiempos, y me viene a la mente, por ejemplo, Laing y su poema "Nudos", Berton Becket y su "Cómo es" o Lewis Carroll con los diálogos de Alicia en el País de las Maravillas, donde la razón es ya una realidad desvinculada de todo lo establecido. Pero más extremosa es aun la fórmula que Tristán Tzara utilizó para estructurar lo que vendría a ser un poema.

Estas incesantes y diversas manifestaciones artísticas del último siglo no deben ser otra cosa que el producto mismo y precipitado de la naturaleza vigilante, propia del hombre, que asimila, para asegurar su sobrevivencia, los estímulos del medio.

Se puede divagar sobre muchos artistas de cualesquiera de las Bellas Artes y llegar a la misma incapacidad que tiene la arquitectura de ser una de ellas.

Casi olvidado en mi mente estaba el caso del "gran" Le Corbusier (el cuervo) con su escala de "modulor" o con las proporciones de Vitrubio... o, como los matemáticos la llaman, "La serie de Fibonacci", con la que se acerca bastante a la proporción áurea (así la razón de $86: 140$ da lugar a la serie: $33,53,86,140,226,366 \ldots$.). Todas prolongadas hasta el infinito en ambas direcciones, pero la continuidad de Le Corbusier que escogió la razón 183: 86 no garantiza ninguna continuidad: solo la sugiere.

Este tipo de demostraciones dan pesadas explicaciones; todas basadas en proporciones "ideales". Yo, por mi parte, no creo que haya diferencia entre un arte basado en proporciones matemáticas y otro de naturaleza intuitiva...

\section{Confesiones y reflejos}

Hasta llegué el otro día a pensar que todo es algo un tanto impersonal, y esa es casi mi realidad-relación con el resto del mundo. Yo 
no sé qué les interesa a ellos ni lo poco que me interesa ya a mí la realidad. Lo único que sé después de todo el tiempo transcurrido en mi vida es que de lo que he amado, he sentido, tenido o perdido... lo único que me ha quedado es mi pintura y todo aquello que está en relación conmigo mismo. Volteo y veo que vivo en una casa vacía (y llegarás a una casa vacía... eso es lo cierto).

Estoy despoblado. Nada me rodea; ni una presencia, ni un abrazo a cualquier hora del día. Lo que me acontece es siempre dentro de mi taller. Mi casa y mi taller, que no son lo mismo. La primera es un teatrín armado como si viviese una familia (cosa que no es cierta), y mi taller es el cerebro de esta casa-realidad. Allí es donde ocurre todo, hasta los más insignificantes sucesos. Decisiones de toda índole: el almuerzo del día, si se pasa cera o se limpian los vidrios, las deudas con el banco, los inventarios, el ver las estrellas, escribir, rabiar, las alarmas, pintar, crear. Podría seguir la secuencia, pero esto es solo la muestra de un botón de miles de ojales de mi realidad.

Una vez quise un piano y el piano llegó; también deseé amar a una mujer. Amo, pero ya no creo mucho en ello. Los amores pasan, las mujeres habidas ya no están; y me digo que esto es como una "sala de espera en una estación de tren". Todo el mundo que pasa por aquí está de tránsito, y lo único que nunca se fue en casi toda mi vida es mi pintura. Así, ella y yo tenemos una prioridad secreta: amarnos y saber que solo somos ella para mí y yo para ella.

El mundo que trato de reflejar es mi interioridad. Una introspección de todo lo vivido; una búsqueda de todas las partes que hay en mí; luego descifrarlas, entenderlas y que sirvan de "jeroglífico paciente" para cualquier espectador. Solo vivo para eso... y amo, amo mi pintura tanto como ella a mí.

Salgo a la calle y ya tengo un terrible apremio por volver a este "gran vientre materno" en el que me espera ella. Siempre me levanto a pintar, pero hay días que no hago otra cosa más que leer, pensar, escribir y sentir que uno siempre es más cruel con lo que ama que con las personas que nos aman.

La crueldad con que nos tratamos (la pintura y yo) es traducida solo en el esfuerzo de intentar ser lo más unidos posible. Se puede pensar que aquello es solo una visión idealista y melancólica entre 
nosotros. Pero, en fin, es así y nada va a cambiar. Este es un pequeño discurso de lo que puede ser mi vida. Un día dejé el cuadro a la mitad y al regresar, al día siguiente, el cuadro ya se había cerrado, cual virgen persistente; sin nada que hacer hasta que la impertinencia se transformase en un chiste de ese momento.

Este escrito da fe y representa la lucha y la unión que queda al resolver un cuadro o nuestros propios dilemas.

\section{Negación inicial a la creación}

Esto es parte del proceso de un cuadro que se resistía a ser creado. Desde las 8 de la noche que lo reempecé, el cuadro estaba dispuesto a "no abrirse", y con el tiempo he llegado a conocer que esta es la única forma de poder hacerlo. A las 10 a.m. el cuadro ya estaba sin terminar pero resuelto. Es solo un testimonio de una batalla entre ella y yo.

Quizá este ritual solo sirva en la mente de uno para deshacer aquel "autismo" en que se cierra una pintura a la mitad o un poco antes de realizarla y no hay forma de retomar el trabajo.

Si se aplica el bermellón, no es.

Si se hace una curva, no es.

Si se dibuja un ojo, debió ser la boca.

Si el fondo debe ser azul, no es.

Si se pinta amarillo, cerúleo, prusia, viridian... no es y no son.

Si uno creía que el cuadro era vertical, no es... entonces se coloca horizontal y tampoco es.

Lo quieres borrar y te das cuenta de que el cuadro está bien. Lo único que sucede es que "se cerró" antes de tiempo, como una puerta trancada con candado, chapa en cruz, o de cuatro golpes, Cantol o cualquier sistema de seguridad... simplemente el cuadro SE CERRÓ, es impenetrable por todas sus partes... Lo que viene a continuación, por soez, vulgar, colérico, grosero y lo que pueda parecer que sea, es la única forma de entrar otra vez en la pintura.

La pintura es la "gran amante". Se cerró porque dejaste pasar un tiempo más allá del limitado y te separaste de ella, la sacaste de tu 
cabeza por otras razones que la convierten en la peor amante, llena de celos de mierda. No quedan argumentos válidos.

Es una dama ofendida, y este es el único sortilegio con el cual puede el cerebro ponerse en una misma frecuencia, la de ella... Aquí vamos.

Con la indiferencia que me ves caer al suelo en pedazos...

Mierda. Hija de puta. Maldita seas... No tengo más que cólera y odio por ti en este momento... No he visto amante más puta o triste que tú, desgraciada. Ni sabes quién es tu padre o tu madre, bastarda de todo. Si te dijera que te he parido tendrías que decir que es cierto...

Así te vi desde el año 51... Desde entonces me jodiste la médula espinal y medio cerebro de mierda que tengo ahora casi todo a tu servicio, a tus ambiciones interminables y desmesuradas... Por ahora, por antes y por todos los años que vendrán... fuck you, fuck you, fuck your dirty ass... you, darling, you honey woman... Do you understand? I hope you leave and die inside a water closer... Bastard. I don't need your love, and I never needed it... Siempre has sido así de posesiva, acaparadora...

Amante llena de celos, de posturitas idiotas; llena de gracias complicadísimas e indescifrables; llena de cansancios, de mis insultos y euforias... Eres la mujer que no encontraría jamás sin haberla buscado así... De complaciente no tienes ni un pelo. Estás hecha de mis sudores, de mis sueños, mis angustias, de mi tiempo (casi todo mi tiempo), de mi vida, de dudas, debilidades, inseguridades, temores y atrevimientos, y de esas ganas de romperte en pedazos. Nunca me había entregado así a nadie, hasta que te conocí... No te dejaría por nada, porque hoy - esta noche de mierda - te has volteado celosa y quieres ponerte fea como siempre lo has hecho... Te esperaré y sé que llegarás a este puerto de eternidades que se nos acaban a ambos. Un beso o dos, o 548 besos... Tú y yo aquí, desgraciada... Amante cruel, monógama de celos, convicciones y rebeliones.

Doy todo de mí para terminar esta pintura, este cuadro, esta superficie llena de color... mala mujer, mujer mía, amante atroz, despiadada y mía... siempre mía.

Al final del amanecer, ella "se abrió" y pude concluir el cuadro. Sin este ritual, que puede parecer quizá grotesco, vulgar y soez, no podría retomarlo y terminarlo. 


\section{Popularidad}

Hay pintores que transmiten un hallazgo que tuvieron repetidamente a través de toda su obra. Unos se hacen propios de un estilo determinado y allí perduran. Otros se sienten gnósticos como almas absolutas del universo; otros están con la moda del momento allí bailando. Los hay de credo o de rebelión contra lo establecido, como una "vanguardia fugaz", pero en verdad lo que no encontramos ya son artistas que tengan la fuerza y la multiplicidad para crear un universo propio; una casi "locación" entre la cordura y la locura. Un estado especial de conciencia que la razón desconoce. De ahí vienen las concepciones que resultan de un hombre que es casi un mismo ser con lo que piensa, decide, hace y se fortifica en él como un cimiento para sus continuos "despertares".

\section{Ensamblajes}

Ítaca te dio la travesía.

Sin ella, no hubieras emprendido

la jornada; y no puede darte más.

Y si la encuentras pobre, no hay engaño.

Te hiciste sabio y experimentado: ya entiendes el sentido de las Ítacas.

C. P. Cavafis

Hubo una época de mi vida en que sentí el suave roce con la muerte. Estaba seguro de que me moriría en cualquier momento y como cualquier mortal. La muerte me buscaba desnuda y sin zapatos. Entonces empecé a idear un soporte donde pudiese dejar todo; una serie de objetos que tenían una fuerte significación para mí. Así, me vino a la mente crear estas estructuras, estos ensamblajes.

Son piezas grandes, extensas, donde podía trabajar con una mayor libertad. La forma a veces estaba en función de aquellos "recuerdos". Así se fue llenando de máscaras mortuorias, relojes de arena, clavos, metales, ábacos, mapamundis, fotos, insectos, telas, estrellas, constelaciones, vitrales, frases y una serie de símbolos 
alusivos a mi lenguaje... fue como un mundo aparte. Era un trabajo rudo, laborioso, por el cambio continuo de materiales.

Cada proyecto era dibujado en la pared o el suelo. Mover cada fracción de la obra la hacía quebrase o quedarse sin brazos. Durante esos meses, mi vida a su alrededor se empezó a despoblar y los trabajos eran parte de lo que no me llevaría a un más allá jamás. Me quedé casi sin nada. Realicé seis. Se expusieron y ahora los tengo almacenados, como si estuviesen en mi memoria. La muerte me encontró pobre y enriquecido por otro misterio incomprensible para ella. Se siguió de frente y desde entonces no nos hemos vuelto a hablar.

\section{Límites}

Desde hace cinco siglos por lo menos, el arte o los artistas han "gozado" de muchas enfermedades mentales y graves problemas de esquizofrenia, maniaco-depresión y/o grave depresión, además de alcoholismo, drogadicción...

Este texto puede dar una idea más clara sobre lo que quiero decir:

Abraham Lincoln / Virginia Woolf / William Blake / Eugene O’Neil / Ludwig van Beethoven / León Trotsky / Vaslov Nijinsky / Tennessee Williams / John Keats / Vincent van Gogh / Isaac Newton / Ernest Hemingway / Sylvia Plath / Miguel Ángel / Winston Churchill / Vivian Leigh / Johan Wolfgang von Goethe / Charles Dickens / Francisco de Goya / Ezra Pound / Antonin Artaud / Arthur Rimbaud / Jean Paul August / Strindberg / Gustav Klimt / James Ensor / Joel Peter Witkin / Patty Duke.

Estas son personas con transtornos mentales que han enriquecido nuestras vidas.

\section{Camino}

Hay personas bien "intencionadas" que me reclaman recalcitrantemente que por qué no pinto seres más "monstruosos", tétricos, grotescos o deformemente angustiados. No me gusta aquella exigencia que demanda la permanencia en el pasado, en una época 
que fue así o asá, o respondía a otra realidad. Lo que hago ahora no lo comparo, ni me veo en la obligación o compromiso de tener que perseverar en ello.

Mi idea es trabajar dentro de la mayor honestidad posible sobre lo que quiero expresar. Si estoy en una época más calmada, menos angustiosa, más introversial, poco me importa tener que recurrir a "monstruos" por querer complacer a uno o a todos. Simplemente intento ser lo más libre posible en mi modo de trabajar o en la elección de un tema.

Nadie puede darme órdenes ni servirme de guía. Después podré ser criticado, pero ya es tarde. La obra se ha consumado. Ha gustado de la libertad. La tarea ha sido ardua, pero ha valido la pena. Creo que ella reproduce muy bien lo que torpemente trato de decir. Hay artistas que tienen una capacidad extraordinaria para decir lo que no hacen o creo yo que no hacen. La mayoría de las grandes frases que se dicen son falsas, y la misma mayoría de grandes frases que se dicen son ciertas. A esta última idea se le podría aplicar el Principio del Tercio Excluso.

\section{Obras maestras}

Creo que la Mona Lisa y la Virgen de las rocas son quizá las dos obras más logradas de Leonardo da Vinci. Son las de primera categoría; las otras vienen después, lejos de ellas... Lo creo.

Es muy difícil encontrar en un pintor una, dos o a lo mejor tres obras importantes. El resto es secundario o terciario, y su obra ya es de segunda. Van Gogh tendrá tres grandes cuadros (los girasoles, la noche estrellada y otro más). Picasso, ninguna. Las damas de Avignon digamos que es la representativa del Cubismo y Guernica viene a ser para mí un dibujo a un solo color. Creo que Picasso como pintor vale menos que como escultor, y quizá sea el mejor escultor del siglo XX (esto ya vienen a ser opiniones).

En resumen, a veces es difícil encontrar una sola obra maestra en muchos pintores o en la mayoría. Es difícil asimilar esta idea, pero la creo más cierta que errónea. 


\section{Tilsa}

Creo que fue en el año 1974 cuando estaba yendo a la Católica para hacer una carpeta de grabados. Llegaba una mañana cuando me crucé con una mujer pequeña, delgada, con un traje seudo campesino, de una tela floreada y un bordado en el pecho. Antes de morir me regaló aquel vestido, y en vez de tenerlo guardado y por no saber cuál sería su fin, lo fui poniendo en los ensamblajes y en los vitrales. Nos saludamos y luego estábamos trabajando en el mismo salón.

Desde entonces -y durante casi diez años- nos volvimos amigos, pintores, creadores cada uno por su lado, y más, y más diría yo. Ojalá en alguna época de mi carrera hubiese tenido influencia de ella. Fue -a mi parecer-, sin dudas, la mejor artista peruana. Vivía en un pasaje cerca del Campo de Marte... y allí empezamos...

En una cama gigantesca que habíamos hecho en su sala; cubierta con una tela del Señor de los Milagros que me habían dado de algún balcón municipal para esa fecha. Allí comíamos, conversábamos y oíamos a su hijo (Gilles Mercier) tocar el piano durante horas. Después que enfermó se mudó a otro barrio. Allí empezó su agonía.

Pintábamos. Ella muy poco cada día. Yo la llevaba del taller a su cama. A veces sentía que ya no pesaba nada. Para crear ilusiones, empezamos a diseñar un taller en Shangai-la donde viviríamos y trabajaríamos. Ella fue una sola vez, yo trataba de demorar la casataller para crear más ilusiones vagas... En fin, allí terminó la cosa.

Una vez muerta, al llegar su cajón a la iglesia donde se velaría el cuerpo, abrí el féretro y la acomodé. Tenía el rostro y las manos blancas-azulinas (al igual que todos los muertos que he visto). La miré. Le di un beso y cerré el ataúd. Siento que es difícil perder a un amigo o amiga como ella. Era una pluma liviana que se elevaba al viento, creando un ambiente lleno de amor y madreselvas.

A veces en las noches la recuerdo, y triste me duermo. Fue una gran mujer y una gran pintora. Sin embargo, creo que poco a poco a Tilsa se le va olvidando como se olvidan todos de los muertos. Espero sinceramente que esta vez no sea así. 


\section{Colofón}

Termino de pintar y guardo aquel cuadro. Ya no tengo interés en él. Poco a poco se va el apego de realización que le tenía. Ahora es solo un lienzo pintado y colocado contra una pared. Pienso que uno no debe enamorarse nunca de los cuadros. Si un pintor lo hace, luego se vuelve un pedante y un presumido ante él mismo y para los demás.

A cuento de qué venía esto... Ya no lo sé. Estoy cansado de esta entrevista. Creo que ha sido mucho tiempo el invertido. En lugar de esto debí haber estado pintando o leyendo. Los pintores no deberían hablar mucho, o poco. Me callo. Fin. 